\title{
Positive Effects of Different Drug Forms of Silybin in the Treatment of Metabolic Syndrome
}

\section{PORUBA ${ }^{1}$, Z. MATUŠKOVÁ ${ }^{1}$, L. KAZDOVÁ ${ }^{2}$, O. OLIYARNYK ${ }^{2}$, H. MALÍNSKÁ ${ }^{2}$, I. TOZZI DI ANGELO ${ }^{3}$, R. VEČĚ̌A ${ }^{1}$}

${ }^{1}$ Department of Pharmacology, Faculty of Medicine and Dentistry, Palacký University Olomouc, Czech Republic, ${ }^{2}$ Center of Experimental Medicine, Institute for Clinical and Experimental Medicine, Prague, Czech Republic, ${ }^{3}$ Department of Exercise Medicine and Cardiovascular Rehabilitation, University Hospital Olomouc, Czech Republic

Received September 14, 2015

Accepted October 12, 2015

\section{Summary}

Silymarin and silybin are widely used for their hepatoprotective properties. Our previous studies confirm positive effect of silymarin on lipoprotein profile and lipid homeostasis. Advanced drug forms may improve the bioavailability of these compounds. In this study, we investigate the effects of silybin in different drug forms (standardized silybin, micronized silybin, and silybin in form of phytosomes) on dyslipidemia and glucose metabolism in hereditary hypertriglyceridemic (HHTg) rats. Male $\mathrm{HHTg}$ rats were divided into four groups of seven animals and were fed by experimental diets. Silybin significantly decreased serum level of triglycerides in groups of rats fed by standardized silybin and silybin in form of phytosomes compared to control group. Results show that silybin did not affect the total cholesterol level, but significantly increased the levels of HDL cholesterol in all groups of animals. Silybin in a standardized form had the highest hypotriglyceridemic effect. On the other hand, the micronized form has caused the highest increase of protective HDL and most significantly decreased glucose and insulin levels. Our results suggest that silybin is probably responsible for some positive properties of silymarin. Subsequent dose-dependent studies of silybin action may reveal the intensity of its positive effects on lipid and glucose parameters.

\section{Key words}

$\mathrm{HHTg}$ rats • Hyperglycemia • Hyperlipidemia • Metabolic syndrome • Silybin

\section{Corresponding author}

R. Večeřa, Department of Pharmacology, Faculty of Medicine and Dentistry, Palacký University Olomouc, Hněvotínská 3, 77515 Olomouc, Czech Republic. E-mail: vecera@seznam.cz

\section{Introduction}

Metabolic syndrome (MS) is a cluster of co-occurred metabolic risk factors associated with cardiovascular morbidity, mortality, and development of type 2 diabetes (Galassi et al. 2006, Mottillo et al. 2010). Diagnostic criteria for MS described by International Diabetes Federation (IDF) include elevated levels of triglycerides and fasting glucose, reduced levels of highdensity lipoproteins, elevated blood pressure as well as increased waist circumference (Alberti et al. 2009). Although triglycerides, cholesterol and glucose play a role in many physiological functions and are necessary for the organism, their elevated levels are pathological. Hyperlipidemia, hyperglycemia, and process of inflammation are the most common risk factors for the development of civilization cardiovascular diseases atherosclerosis, heart attack, stroke, or peripheral arterial disease (Brown et al. 2010, Weber and Noels 2011).

There are several terms that are important for understanding of this issue. One of the enzymes, participating in the endogenous synthesis of cholesterol, is 3-hydroxy-3-methylglutaryl-coenzym A reductase, which is a target in the treatment of hypercholesterolemia. Thereafter, the cholesterol is transported in 
the organism. Low density lipoprotein cholesterol (LDL-Ch) represents transport of cholesterol from the liver to the peripheral tissues; on the other hand, high density lipoprotein cholesterol (HDL-Ch) is responsible for the reverse transport of cholesterol. Moreover, HDLCh exhibits anti-atherogenic properties and has protective effects in patients suffering from the atherosclerosis (Navab et al. 2011, Barter et al. 2007). Insulin, as a hormone released from the pancreatic islets, is also important to mention. People suffering from metabolic syndrome often have an impaired metabolism of glucose - the cells do not respond to elevated levels of insulin. These patients have then a high risk of type 2 diabetes development.

There is currently no drug that could affect all of these components relating to metabolic syndrome. For example, the hypertriglyceridemia is usually treated by fibrates that stimulate receptors activating enzymes involved in the catabolism of triglycerides. In the case of hypercholesterolemia, the first choice of drug is a statin. Statins are a group of drugs which are known to inhibit de novo cholesterol synthesis in the liver. Patients suffering from type 2 diabetes are usually dependent on the treatment with drugs that stimulates insulin secretion (sulfonylurea derivatives), insulin sensitizers (metformin) or application of exogenous insulin or its analogues.

Herbal remedies available for the supportive therapy or the treatment of these states are extracts of plants rich in polyphenols. One of the medicinal plant rich in polyphenol compounds is milk thistle, Silybum marianum (Asteraceae). Silymarin (extract from seeds of milk thistle) is a mixture of flavonoids traditionally used for the digestive and liver disorders (Valenzuela and Garrido 1994), and also for its hypocholesterolemic effects (Skottová and Krecman 1998). Major component of silymarin is silybin - compound responsible for many positive properties of silymarin. Silybin is traditionally used for the treatment of Amanita phalloides poisoning and even recently is used for the prevention of complication associated with liver transplantation (Enjalbert et al. 2002, Ferenci and Beinhardt 2013). All properties of standardized silymarin resp. silybin are well established, unfortunately poor bioavailability (approximately $2 \%$ of administered dose) and rapid elimination limits its therapeutic potential (Calani et al. 2012). Micronized silymarin resp. silybin provides approximately $85 \%$ increase in bioavailability than in the case of standardized form. Silymarin and silybin in form of phytosomes show a very good bioavailability in rats reaching 6-10 times improvement compared to a standard form (Morazzoni et al. 1992, 1993, Kidd and Head 2005).

In this study, we focused on the influence of the application of silybin in different forms on the serum levels of triglycerides, cholesterol, HDL-Ch, glucose, and insulin in the animal model of metabolic syndrome hereditary hypertriglyceridemic rats (HHTg). These rats were bred from Wistar rats on the basis of a high sucrose diet-induced increase in plasma triglycerides. These rats are a suitable model for phenotyping and genotyping such complex diseases as hypertension, hypertriglyceridemia, insulin resistance, liver steatosis and others, which represent components of the metabolic syndrome. (Klimes et al. 1995, Stolba et al. 1992, Vrána and Kazdová 1990, Zicha et al. 2006).

\section{Materials and Methods}

\section{Animals and design of experiment}

The experiments were carried on male 4 months old hereditary hypertriglyceridemic (HHTg) rats from the Institute for the Clinical and Experimental Medicine, Prague, Czech Republic. Standardized silybin and micronized silybin for preparation of diets were purchased from Favea, s.r.o., Koprivnice, Czech Republic. Silybin in the form of phytosomes was obtained from Indena S.p.A., Milan, Italy.

HHTg rats were housed in an air-conditioned animal facility and allowed free access to food and water. Animals were divided into four groups (seven rats in each group) and were fed for 4 weeks by standard laboratory diet (STD, control group), or the same diet supplemented with $0.5 \%(\mathrm{w} / \mathrm{w})$ of standardized silybin (SSD), or $0.5 \%$ (w/w) of micronized silybin (MSD), or $0.5 \%(w / w)$ of silybin in form of phytosome (PSD). This period was selected according to previously published results (Skottová et al. 2003, Orolin et al. 2007, Vecera et al. 2011). The amount of consumed feed was checked 3 times a week.

After 4 weeks, rats were sacrificed in the postprandial state without anesthesia, since both the metabolic syndrome and cardiovascular events are related to non-fasting triglycerides and other postprandial metabolic variation (Nordestgaard et al. 2007).

All experiments were performed in accordance with the Animal Protection Law of the Czech Republic $311 / 1997$ which is in compliance with the European Community Council recommendations for the use of laboratory animals $(86 / 609 / \mathrm{ECC})$ and were approved by 
the Ethical Committee of the Ministry of Education, Czech Republic.

\section{Lipid parameters assay}

Serum triglycerides and cholesterol content was determined by enzymatic assay (Erba-Lachema, Brno, Czech Republic).

\section{Glucose and insulin analysis}

Blood glucose levels were measured by the glucose oxidase assay (Erba-Lachema, Brno, Czech Republic) with the use of tail vein blood and $5 \%$ trichloroacetic acid. Serum insulin concentrations were determined using the Mercodia Rat Insulin ELISA kit (Mercodia AB, Uppsala, Sweden).

\section{Statistical analysis}

All data are expressed as mean \pm SD $(n=7)$. ANOVA analysis of variance and post-hoc Fisher LSD test were used. Data in all groups had Gaussian distribution and were analyzed at the significance level of 0.05. Statistical analysis was performed using software Statistica Cz 12 (StatSoft CR, Prague, Czech Republic).

\section{Results}

Supplementation with all forms of silybin extracts did not differ among group. No significant differences in body weight between groups were observed (STD: $368 \pm 7 \mathrm{~g}$; SSD: $352 \pm 4 \mathrm{~g}$; MSD: $366 \pm 11 \mathrm{~g}$; PSD: $361 \pm 7 \mathrm{~g}$ ).

Effects of silybin on serum level of cholesterol and triglycerides

As shown in Figure 1A, four weeks silybin treatment significantly decreased serum level of triglycerides by $37 \%(\mathrm{p}<0.001)$ in rats fed by standardized silybin and by $31 \%(\mathrm{p}<0.01)$ in rats treated by silybin in form of phytosomes in comparison with control animals. On the other hand, a non-significant decrease of serum level of triglycerides was observed in animals treated by micronized silybin compared to control group.

As regards the serum level of total cholesterol, no differences between all groups were found (Fig. 1B).

The Figure 1C summarizes the effects of silybin treatment on the HDL-cholesterol level. The administration of silybin (in all used forms) significantly increased serum level of HDL-Ch in experimental rats compared to control rats. The increase of serum level of HDL-Ch was by $87 \% \quad(\mathrm{p}<0.001)$ for rats fed by standardized silybin, by $61 \%(\mathrm{p}<0.01)$ for rats fed by micronized silybin, and by $97 \%(p<0.0001)$ for animals fed by silybin in form of phytosomes.

A

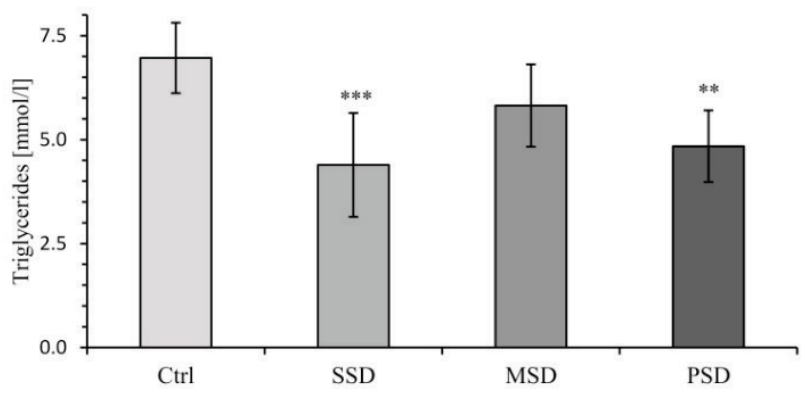

B
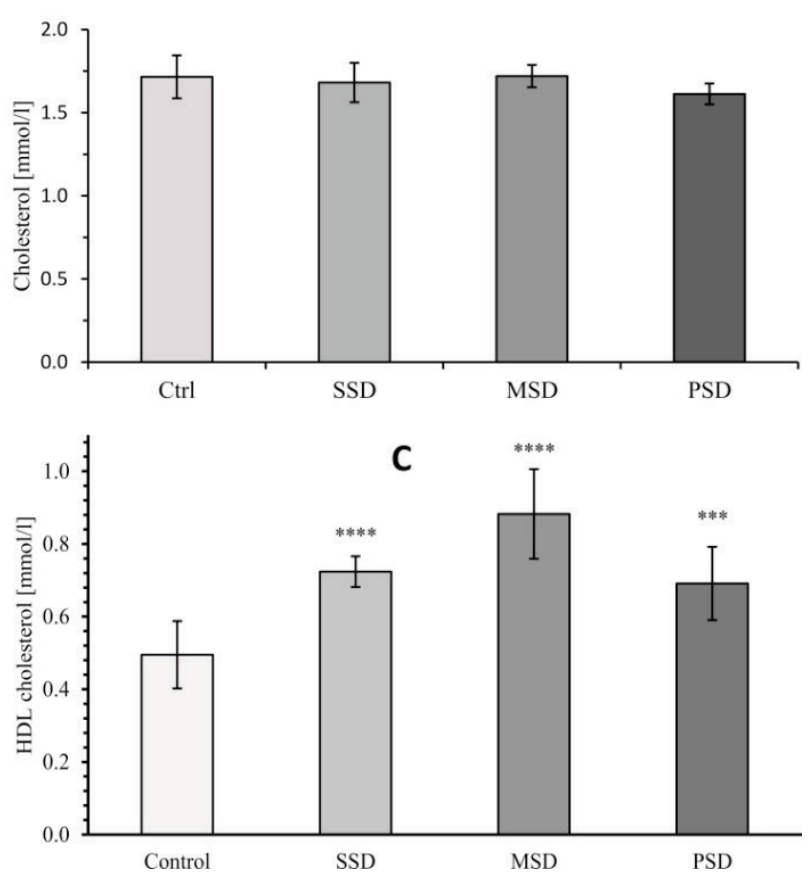

Fig. 1. Effects of standardized silybin (SSD), micronized silybin (MSD) and silybin in form of phytosome (PSD) on triglycerides serum level (A), serum cholesterol level (B) and HDL cholesterol level (C). Data are expressed as mean with $\pm S D, n=7$. $* * \mathrm{p}<0.01$ vs. Control; *** $\mathrm{p}<0.001$ vs. Control; **** $\mathrm{p}<0.0001$ vs. Control (standard laboratory diet).

\section{Effects of silybin on glucose and insulin content}

The results in Figure 2 summarize the effects of four weeks treatment with silybin on glucose level (A) and insulin level (B). Serum level of glucose was significantly decreased by $10 \%(\mathrm{p}<0.001)$ in rats fed by standard laboratory diet containing standardized silybin and by $22 \%(\mathrm{p}<0.0001)$ in animals fed by micronized silybin compared to control group. Similarly, the level of 
insulin was significantly decreased by $33 \%(\mathrm{p}<0.01)$ in animals treated by standardized silybin and by $47 \%$ $(p<0.01)$ in rats with application of micronized silybin. For both parameters, glucose and insulin levels were non-significantly decreased in the rats fed by standard laboratory diet containing silybin in form of phytosomes.

\section{A}

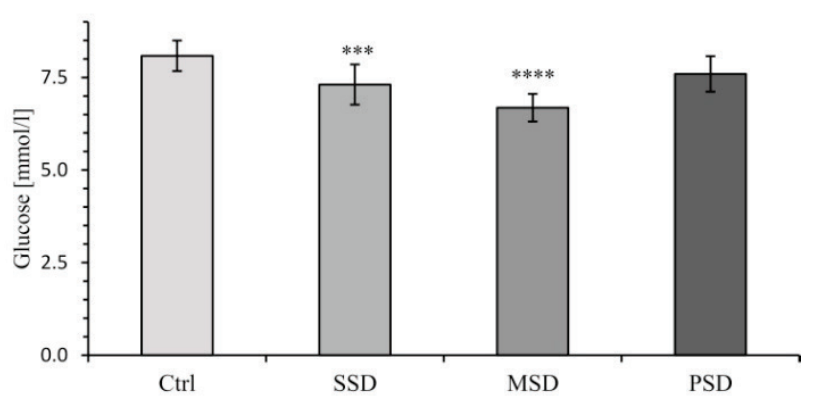

B

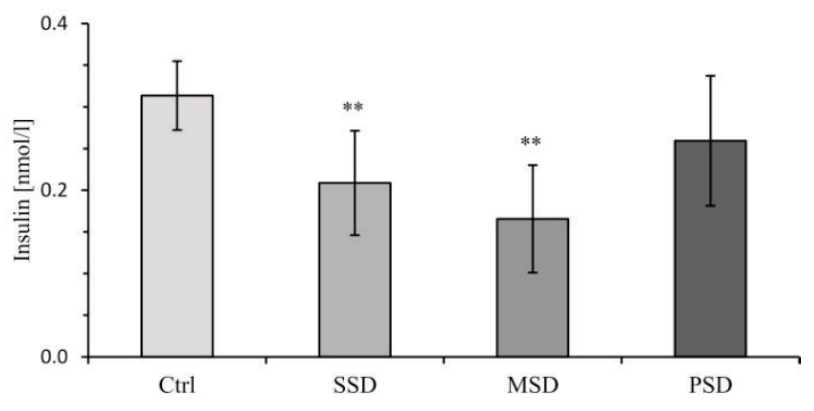

Fig. 2. Effects of standardized silybin (SSD), micronized silybin (MSD) and silybin in form of phytosome (PSD) on serum glucose level (A) and serum insulin level (B). Data are expressed as mean with $\pm \mathrm{SD}, \mathrm{n}=7$. $* * \mathrm{p}<0.01$ vs. Control; $* * * \mathrm{p}<0.001$ vs. Control; **** $\mathrm{p}<0.0001$ vs. Control (standard laboratory diet).

\section{Discussion}

Patients suffering from metabolic syndrome have a high risk of cardiovascular morbidity and mortality that are highly associated with hypertriglyceridemia, hypercholesterolemia and impaired glucose metabolism (Cullen 2000). The main target of pharmacotherapy is the amelioration of this metabolic disorders. In this study, we found the positive effects of silybin, polyphenol isolated from the extract silymarin, on lipoprotein profile and glucose metabolism in hereditary hypertriglyceridemic (HHTg) rats - an accepted animal model of metabolic syndrome (Vrána and Kazdová 1990, Zicha et al. 2006). This non-obese strain, selected from Wistar rats, exhibited dyslipidemia, hyperinsulinemia, resistance of peripheral tissues to insulin action and impaired glucose tolerance (Vrána et al. 1993).
In the current study, we observed that the administration of silybin significantly increased levels of protective HDL-Ch after feeding of all experimental diets. On the other hand, the silybin diets did not significantly change the serum level of total cholesterol in HHTg rats in comparison with control HHTg rats. These results are consistent with our previous findings based on the observation of positive effect of silymarin in rats fed by high-cholesterol diet. The administration of silymarin and polyphenolic fraction positively increased the HDL-Ch content without effect on plasma level of total cholesterol (Skottová et al. 2003). In our other previous study, silymarin administered to HHTg rats significantly increased the content of HDL-Ch and significantly decreased the total cholesterol and triglyceride levels in comparison with control HHTg rats (Poruba et al. 2015). The silymarin administered to normotriglyceridemic rats significantly decreased cholesterol content in the plasma and significantly increased HDL-Ch level (Sobolová et al. 2006). Concurrently, we observed that silymarin in developed drug form provides more increased efficacy than silymarin in standardized form (Poruba et al. 2015). There are also clinical data about the hypolipidemic action of silymarin. In 2006, the clinical study showed that silymarin significantly decreased the level of triglycerides total cholesterol and improved glucose tolerance in patients suffering from type 2 diabetes (Huseini et al. 2006). The hypolipidemic action of silybin and silymarin is still not well understood. In our previous study, we tried to evaluate the possible mechanism of action of silymarin. We found that silymarin upregulates the CYP7A1 protein content and probably increases the bile acids secretion - one of the most important elimination pathways of cholesterol from the body (Poruba et al. 2015). In comparison with silymarin that is used as a positive control in some studies for the efficacy evaluation, the literature data for silybin are still lacking (Zhang et al. 2013).

Silymarin and related compounds seem to be also important supplements for the type 2 diabetes treatment (Huseini et al. 2006, Hussain 2007, Suksomboon et al. 2011). As regards silybin, we are the first who found it had a beneficial effect on glucose tolerance. Our results also indicate that silybin seems to be responsible for the beneficial effect of silymarin on glucose metabolism. In our study, silybin significantly decreased the blood glucose level and insulin level. All these markers are related with the risk of type 2 diabetes and metabolic syndrome development (Grundy 1999). 
Low silybin bioavailability highly limits its therapeutic use. For this reason, drug forms with increased absorption were developed. One of the possible ways to increase the bioavailability is the micronization or developing drug forms in complex of phytosomes. The literature shows about $85 \%$ increase of bioavailability for the micronized form of silybin and more than 6 times improvement of bioavailability for phytosomes forms compared to standard form of silybin (Morazzoni et al. 1992, 1993, Kidd and Head 2005). Effects of silybin at a dosage used were so pronounced, that only small differences in the efficiency of individual forms were observed. Subject to further studies should be test lower doses of each form of silybin on other disturbance of lipid and carbohydrate metabolism associated with metabolic syndrome or type 2 diabetes.

In conclusion, our results suggest that silybin itself seems to be beneficial for the hypertriglyceridemia and hyperglycemia supportive therapy. Despite our expectation, silybin administration did not influence the total cholesterol level, but significantly increased the protective high density lipoprotein content. Silybin in a standardized form had the highest hypotriglyceridemic effect. On the other hand, the micronized form of silybin has caused the highest increase of protective HDL and most significantly decreased glucose and insulin levels in rats suffering from the metabolic syndrome. Future dosedependent studies of silybin effects may disclose the intensity of its positive influence on glucose and lipid parameters. Our results suggest that silybin (the main component of silymarin) is probably responsible for some positive properties of this extract. Further studies are needed to elucidate the mechanism of these positive effects of silybin.

\section{Conflict of Interest}

There is no conflict of interest.

\section{Acknowledgements}

This study was supported by grant P303/13-10813S from the Czech Science Foundation, Czech Republic.

\section{References}

ALBERTI KG, ECKEL RH, GRUNDY SM, ZIMMET PZ, CLEEMAN JI, DONATO KA, FRUCHART JC, JAMES WP, LORIA CM, SMITH SC JR: Harmonizing the metabolic syndrome: a joint interim statement of the International Diabetes Federation Task Force on Epidemiology and Prevention; National Heart, Lung, and Blood Institute; American Heart Association; World Heart Federation; International Atherosclerosis Society; and International Association for the Study of Obesity. Circulation 120: 1640-1645, 2009.

BARTER PJ, PURANIK R, RYE KA: New insights into the role of HDL as an anti-inflammatory agent in the prevention of cardiovascular disease. Curr Cardiol Rep 9: 493-498, 2007.

BROWN A, REYNOLDS LR, BRUEMMER D: Intensive glycemic control and cardiovascular disease: an update. Nat Rev Cardiol 7: 369-375, 2010.

CALANI L, BRIGHENTI F, BRUNI R, DEL RIO D: Absorption and metabolism of milk thistle flavonolignans in humans. Phytomedicine 20: 40-46, 2012.

CULLEN P: Evidence that triglycerides are an independent coronary heart disease risk factor. Am J Cadiol 89: 943-949, 2000.

ENJALBERT F, RAPIOR S, NOUGLIER-SOULÉ J, GUILLON S, AMOUROUX N, CABOT C: Treatment of amatoxin poisoning: 20-year retrospective analysis. J Toxicol Clin Toxicol 40: 715-757, 2002.

FERENCI P, BEINHARDT S: Silibinin: an old drug in the high tech era of liver transplantation. J Hepatol 58: 409-411, 2013.

GALASSI A, REYNOLDS K, HE J: Metabolic syndrome and risk of cardiovascular disease: a meta-analysis. Am $J$ Med 119: 812-819, 2006.

GRUNDY SM: Hypertriglyceridemia, insulin resistance, and the metabolic syndrome. Am J Cardiol 83: $25 \mathrm{~F}-29 \mathrm{~F}, 1999$.

HUSEINI HF, LARIJANI B, HESHMAT R, FAKHRZADEH H, RADJABIPOUR B, TOLIAT T, RAZA M: The efficacy of Silybum marianum (L.) Gaertn. (silymarin) in the treatment of type II diabetes: a randomized, double-blind, placebo-controlled, clinical trial. Phytother Res 20: 1036-1039, 2006.

HUSSAIN SA: Silymarin as an adjunct to glibenclamide therapy improves long-term and postprandial glycemic control and body mass index in type 2 diabetes. J Med Food 10: 543-547, 2007. 
KIDD P, HEAD K: A review of the bioavailability and clinical efficacy of milk thistle phytosome: a silybinphosphatidylcholine complex (Siliphos). Altern Med Rev 10: 193-203, 2005.

KLIMES I, VRÁNA A, KUNES J, SEBÖKOVÁ E, DOBESOVÁ Z, STOLBA P, ZICHA J: Hereditary hypertriglyceridemic rat: a new animal model of metabolic alterations in hypertension. Blood Press 4: 137-142, 1995.

MORAZZONI P, MONTALBETTI A, MALANDRINO S: Comparative biliary excretion of silybin after single oral doses of silipide and silymarin in rats. First Intl. Symposium on Natural Drugs and the Digestive Tract, Naples, Italy. Seattle, WA: Indena USA Inc.; www.indenausa.com, 1992.

MORAZZONI P, MONTALBETTI A, MALANDRINO S, PIFFERI G: Comparative pharmacokinetics of silipide and silymarin in rats. Eur J Drug Metab Pharmacokinet 18: 289-297, 1993.

MOTTILLO S, FILION KB, GENEST J, JOSEPH L, PILOTE L, POIRIER P, RINFRET S, SCHIFFRIN EL, EISENBERG MJ: The metabolic syndrome and cardiovascular risk a systematic review and meta-analysis. J Am Coll Cardiol 56: 1113-1132, 2010.

NAVAB M, REDDY ST, VAN LENTEN BJ, FOGELMAN AM: HDL and cardiovascular disease: atherogenic and antheroprotective mechanisms. Nat Rev Cardiol 8: 222-232, 2011.

NORDESGAARD BG, BENN M, SCHNOHR P, TYBJAERG-HANSEN A: Nonfasting triglycerides and risk of myocardial infarction, ischemic heart disease, and death in men and women. JAMA 298: 299-308, 2007.

OROLIN J, VECERA R, JUNG D, MEYER UA, SKOTTOVÁ N, ANZENBACHER P: Hypolipidemic effects of silymarin are not mediated by the peroxisome proliferator-activated receptor alpha. Xenobiotica 37: 725-735, 2007.

PORUBA M, KAZDOVÁ L, OLIYARNYK O, MALINSKÁ H, MATUSKOVÁ Z, TOZZI Di ANGELO I, SKOP V, VECERA R: Improvement bioavailability of silymarin ameliorates severe dyslipidemia associated with metabolic syndrome. Xenobiotica 45: 751-756, 2015.

SKOTTOVÁ N, KRECMAN V: Silymarin as a potential hypocholesterolaemic drug. Physiol Res 47: 1-7, 1998.

SKOTTOVÁ N, VECERA R, URBÁNEK K, VÁNA P, WALTEROVÁ D, CVAK L: Effects of polyphenolic fraction of silymarin on lipoprotein profile in rats fed cholesterol-rich diets. Pharm Res 47: 17-26, 2003.

SOBOLOVÁ L, SKOTTOVÁ N, VECERA R, URBÁNEK K: Effect of silymarin and its polyphenolic fraction on cholesterol absorption in rats. Pharmacol Res 53: 104-112, 2006.

STOLBA P, DOBESOVÁ Z, HUSEK P, OPLTOVÁ H, ZICHA J, VRÁNA A, KUNES J: The hypertriglyceridemic rat as a genetic model of hypertension and diabetes. Life Sci 51: 733-740, 1992.

SUKSOMBOON N, POOLSUP N, BOONKAEW S, SUTHISISANG CC: Meta-analysis of the effect of herbal supplement on glycemic control in type 2 diabetes. J Ethnopharmacol 137: 1328-1333, 2011.

VALENZULA A, GARRIDO A: Biochemical bases of the pharmacological action of the flavonoid silymarin and of its structural isomer silibinin. Biol Res 27: 105-112, 1994.

VECERA R, ZACHAROVÁ A, OROLIN J, SKOTTOVÁ N, ANZENBACHER P: The effect of silymarin on expression of selected $\mathrm{ABC}$ transporters in the rat. Vet Med 56: 59-62, 2011.

VRÁNA A, KAZDOVÁ L: The hereditary hypertriglyceridemic nonobese rat: an experimental model of human hypertriglyceridemia. Transplant Proc 22: 2579, 1990.

VRÁNA A, KAZDOVÁ L, DOBESOVA Z, KUNES J, KREN V, BÍLÁ V, STOLBA P, KLIMES I: Triglyceridemia, glucoregulation, and blood pressure in various rat strains. Effects of dietary carbohydrates. Ann N Y Acad Sci 683: 57-68, 1993.

WEBER C, NOELS H: Atherosclerosis: current pathogenesis and therapeutic options. Nat Med 17: 1410-1422, 2011.

ZHANG S, ZHENG L, DONG D, WU L, YIN L, QI Y, HAN X, LIN Y, LIU K, PENG J: Effects of flavonoids from Rosa laevigata Michx fruit against high-fat diet-induced non-alcoholic fatty liver disease in rats. Food Chem 141: 2108-2116, 2013.

ZICHA J, PECHANOVÁ O, CACÁNYIOVÁ S, CEBOVÁ M, KRISTEK F, TÖRÖK J, SIMKO F, DOBESOVÁ Z, KUNES J: Hereditary hypertriglyceridemic rat: a suitable model of cardiovascular disease and metabolic syndrome? Physiol Res 55 (Suppl 1): S49-S63, 2006. 